http://dx.doi.org/10.32929/2446-8355.2020v29n3p348-364

\title{
DESENVOLVIMENTO DO FEIJÃO-DE-PORCO EM LATOSSOLO SUBMETIDO À COMPACTAÇÃO
}

\author{
Daniel Dias Valadão Júnior1*, Flávia Firmini de Lima Souza², Franciele Caroline de Assis \\ Valadão ${ }^{1}$, Caroline Rodrigues Polizel ${ }^{2}$, Rafael Guilherme da Silva ${ }^{2}$
}

\begin{abstract}
${ }^{1}$ Professor (a) Doutor (a) do Instituto Federal de Mato Grosso, Campus Campo Novo do Parecis-MT. *E-mail do autor correspondente: daniel.valadao@cnp.ifmt.edu.br

${ }^{2}$ Aluna (o) do curso Bacharelado em Agronomia do Instituto Federal de Mato Grosso, Campus Campo Novo do Parecis-MT.
\end{abstract}

Recebido: 15/04/2020; Aceito: 15/08/2020.

RESUMO: O tráfego intenso de maquinários pode resultar em uma camada compactada afetando o crescimento das raízes e na produtividade das culturas. $\mathrm{O}$ objetivo deste trabalho foi avaliar o potencial da cultura do feijão-de-porco em solo compactado visando a recuperação de solos degradados. O experimento foi instalado em Latossolo Vermelho Distrófico típico de textura argilosa sob delineamento de blocos casualizados, com quatro repetições. Os tratamentos foram constituídos por compactações obtidas pelo número de passadas de um trator agrícola $(0,1,3,6$ e 11 passadas). As propriedades físicas do solo (densidade do solo, macroporosidade, microporosidade e porosidade total) e o sistema radicular (diâmetro, área de raiz e distribuição) foram avaliados nas camadas de 0,0-0,05, 0,05-0,10, 0,10-0,15 e 0,15-0,20 m de profundidade. Avaliou-se ainda a evolução da cobertura do solo, altura de planta, o conteúdo de nitrogênio $(\mathrm{N})$ na planta e a produção de massa seca (MSPA) do feijão-de-porco. O tráfego de máquinas proporcionou alteração nas propriedades físicas do solo e consequente formação de camada compactada. As mudanças nas propriedades físicas ocasionadas pelo tráfego do trator provocam alterações no sistema radicular do feijão-de-porco, porém, não o suficiente para comprometer a MSPA, altura e cobertura do solo, sendo uma cultura alternativa para rotação de cultura em solos compactados.

Palavras-chave: Canavalia ensiformis DC. Sistema radicular. Taxa de cobertura.

\section{DEVELOPMENT OF JACK BEAN IN COMPACTED LATOSSOLO}

ABSTRACT: Heavy machinery traffic can result in a compacted layer affecting root growth and crop productivity. The aim of this study was to evaluate the potential of the jack bean culture to develop in compacted soil seeking a sustainable alternative for the recovery of degraded soils. The experiment was installed in a Latossolo Vermelho Distrófico típico under a randomized block design with four replicates. The treatments were composed of different levels of compacts obtained by the number of passes of an agricultural tractor $(0,1,3,6$ and 11 passed). The soil physical properties (density, macroporosity, microporosity and total porosity) and root system (diameter, root area and distribution) were evaluated in the layers of $0.0-0.05 ; 0.05-0.10 ; 0.10-0.15$ and $0.15-0.20 \mathrm{~m}$ depth. It was also evaluated the evolution of 
soil cover, plant height, nitrogen content in the plant and dry mass production of the jack bean. The traffic of machines resulted in changes in the physical properties of the soil and consequently the formation of a compacted layer. The changes in the physical properties of the soil cause changes in the root system of the jack bean and in the absorption of nitrogen, however, not enough to compromise the development of the plant, being an alternative crop for crop rotation in compacted soils.

Key words: Canavalia ensiformis DC. Root system. Overage rate

\section{INTRODUÇÃO}

A otimização do sistema de produção das lavouras e o decorrente aumento de produtividade têm grande participação das máquinas e implementos cada vez maiores. Porém, a intensificação do tráfego nas áreas de cultivo contribui para a formação de camadas compactadas, sendo que a profundidade dessa camada pode variar de acordo com as características do solo e das máquinas, e quando superficialmente prejudica com maior intensidade o desenvolvimento das plantas por restringir a camada de solo explorada (VALADÃO et al., 2015; SCAPINELLI et al., 2016). Cabe salientar que a interação soloplanta apresenta-se distinta em função da espécie (GUBIANI et al., 2013), podendo ocorrer interferências negativas quando em solos compactados, principalmente no crescimento radicular (MONTANARI et al., 2012), pois há modificação no fluxo de água e ar no solo (REINERT et al., 2008) com redução do oxigênio disponível (FARIAS et al., 2013), trazendo como consequência a redução significativa da produtividade (REINERT et al., 2008; VALADÃO et al., 2015; SCAPINELLI et al., 2016).

Em leguminosas, diferentes resultados têm sido obtidos quanto à modificação do sistema radicular. VALADÃO et al. (2015) observaram na cultura da soja uma redução de 23\% da área de raiz na camada de 0,0-0,05 m em comparação a área sem compactação com oito passadas de trator. FARIAS et al. (2013) na cultura do feijão, observaram diminuição de aproximadamente $78 \%$ da massa seca da raiz com o aumento da densidade do solo de 1,0 para $1,8 \mathrm{Mg} \mathrm{m}^{-3}$.

Com a adoção de técnicas voltadas para o manejo sustentável do solo, é possível minimizar a compactação dos solos agrícolas, como por exemplo, a utilização de rotação de cultura e plantas de cobertura, contribuindo com a manutenção ou melhoria das características físicas do solo a longo prazo (DOMIT et al., 2014; OLIVEIRA et al., 2012). O uso de leguminosas, em sua maioria, apresenta alto potencial para reciclagem dos macronutrientes e aporte de nitrogênio (N) aos sistemas de produção (TEODORO et al., 2011), reduzindo assim o uso de fertilizantes industrializados nas lavouras.

O feijão-de-porco (Canavalia ensiformis DC) é uma opção de planta de cobertura que pode ser utilizada em consórcio com plantas de interesse comercial e é corriqueiramente recomendada como opção de adubação verde e recuperação de áreas degradadas. A espécie apresenta porte pequeno, rusticidade (quanto às características físicas e químicas do solo), tolerância à seca e ao sombreamento parcial, crescimento inicial lento e efeito alelopático sobre plantas daninhas (EIRAS; COELHO, 2011). Além disso, é uma planta leguminosa com 
sistema radicular constituído por raiz pivotante e um grande volume de raízes secundárias, o que favorece a abertura de pequenas galerias no solo, aumentando a aeração e capacidade de absorção de água do solo (PADOVAN et al., 2011). Apesar dessas características promissoras são raros os trabalhos em que se avalia o feijão-de-porco em solo compactado sob condições de campo. Assim, baseando na hipótese que o feijão-de-porco seja capaz de desenvolver em solos com camadas que apresentem restrições a maioria das culturas, o objetivo deste trabalho foi avaliar o potencial da cultura do feijão-de-porco se desenvolver em solo compactado visando ser uma alternativa sustentável na recuperação de solos degradados.

\section{MATERIAL E MÉTODOS}

A pesquisa foi implantada na área experimental do Instituto Federal de Educação, Ciência e Tecnologia de Mato Grosso, Campus Campo Novo do Parecis, num Latossolo Vermelho Distrófico típico de textura argilosa (SANTOS et al., 2018). As características do solo na camada de 0,0-0,20 m são apresentadas na Tabela 1. A área experimental localiza-se a 1340'31" de latitude Sul; 57 53'31" de longitude Oeste e $572 \mathrm{~m}$ de altitude. O clima da região, segundo classificação de Köppen, é o Aw e os dados de precipitação e pluviosidade do período encontram-se na Figura 1.

Tabela 1. Características químicas e textural do solo da área experimental. Chemical and textural attributes of the soil in the experimental area.

\begin{tabular}{|c|c|c|c|c|c|c|c|c|c|}
\hline $\mathrm{pH}$ & $\mathrm{P}$ & $\mathrm{K}$ & $\mathrm{Ca}$ & $\mathrm{Mg}$ & $\mathrm{Al}$ & $\mathrm{H}$ & MO & Areia & Argila \\
\hline $\mathrm{CaCl}_{2}$ & \multicolumn{2}{|c|}{$\mathrm{mg} \mathrm{dm}^{-3}$} & \multicolumn{4}{|c|}{$\mathrm{cmol}_{\mathrm{c}} \mathrm{dm}^{-3}$} & \multicolumn{3}{|c|}{$\mathrm{g} \mathrm{kg}^{-1}$} \\
\hline 5,5 & 9,2 & 45,4 & 3,0 & 1,8 & 0,0 & 2,92 & 30,4 & 290 & 558 \\
\hline
\end{tabular}

Nota: $\mathrm{pH}\left(\mathrm{CaCl}_{2}\right)$ : solução de cloreto 0,01M, na proporção 1:2,5 (solo: $\mathrm{Ca} / \mathrm{Cl}$ ); Fósforo $(\mathrm{P})$ e Potássio $(\mathrm{K})$ : extraídos com solução de $\mathrm{HCI} 0,05 \mathrm{~N}^{2} \mathrm{H}_{2} \mathrm{SO}$ 0,025N (Mehlich-1); Cálcio (Ca), Magnésio (Mg) e Alumínio (Al): extraídos com solução de cloreto de potássio $1,0 \mathrm{~mol} \mathrm{~L}^{-1}$; Hidrogênio $\left(\mathrm{H}^{+}\right)$: extraído com acetato de cálcio a pH=7; Matéria Orgânica (MO): Oxidação com dicromato de potássio e determinação colorimétrica; Areia, Silte e Argila - dispersante $\mathrm{NaOH}$ e determinação por densímetro. $\mathrm{pH}\left(\mathrm{CaCl}_{2}\right)$ : 0.01M chloride solution, in the proportion 1: 2.5 (soil: $\mathrm{Ca} / \mathrm{Cl}$ ); Phosphorus (P) and Potassium (K): extracted with $\mathrm{HCl}$ solution $0.05 \mathrm{~N}$ and $\mathrm{H}_{2} \mathrm{SO} 0.025 \mathrm{~N}$ (Mehlich-1); Calcium (Ca), Magnesium (Mg) and Aluminum (Al): extracted with $1 \mathrm{~N}$ potassium chloride solution; Hydrogen $(H)$ : extracted with calcium acetate at $p H=7$; Organic Matter $(O M)$ : Oxidation with potassium dichromate and colorimetric determination; Sand, Silt and Clay - NaOH dispersant and determination by densimeter.

Fonte: Autoria própria. Own authorship. 


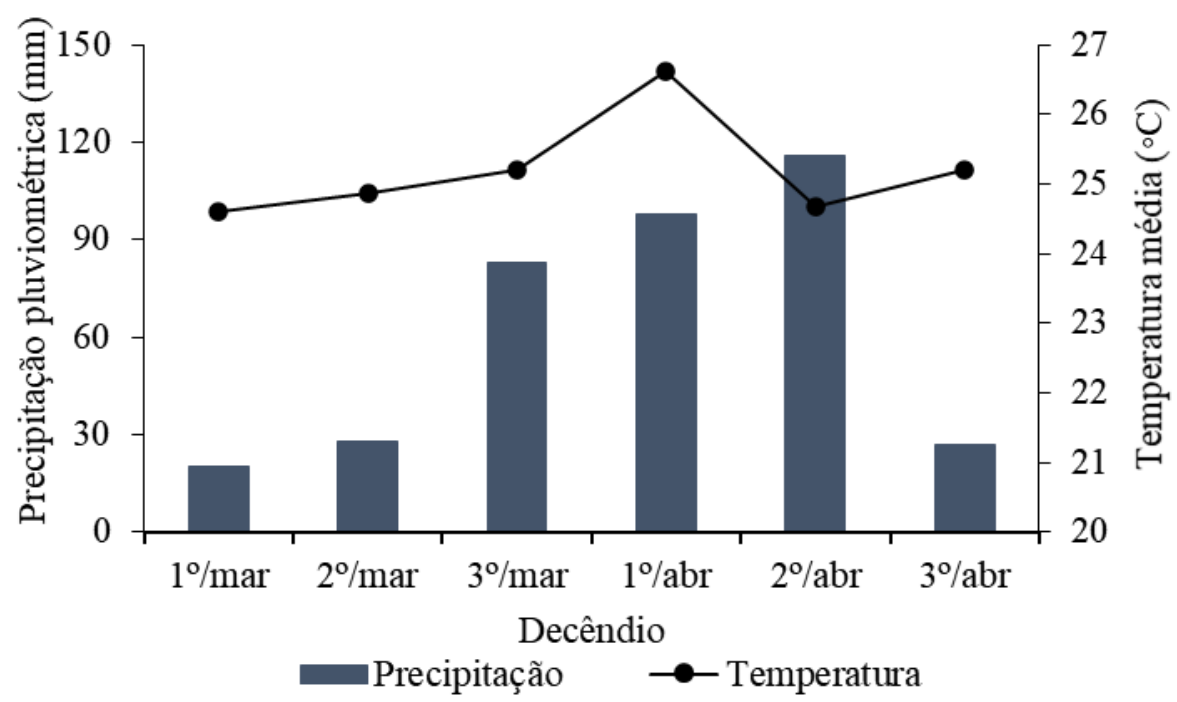

Figura 1. Precipitação pluvial e temperatura média do ar, decêndiais, na área de realização da pesquisa durante o período de março a abril. $1^{\circ} ; 2^{\circ}$ e $3^{\circ}=$ Decêndio de cada mês. Decimal rainfall and average air temperature, in the area of the research, during the period from March to April. $1^{\text {st }} ; 2^{\text {nd }}$ and $3^{\text {rd }}=10^{\text {th }}$ of each month.

Fonte: Autoria própria. Own authorship.

O delineamento adotado foi o de blocos completos casualizados, com cinco tratamentos e quatro repetições. Os tratamentos foram dispostos por diferentes níveis de compactações do solo, a saber: $\mathrm{C}_{0}$, Sem tráfego adicional, $\mathrm{C}_{1}, 1$ passada adicional do trator, $\mathrm{C}_{3}, 3$ passadas adicionais do trator, $\mathrm{C}_{6}, 6$ passadas adicionais do trator, $\mathrm{C}_{11}, 11$ passadas adicionais do trator. As parcelas experimentais foram de $7 \times 3,6 \mathrm{~m}$, com área total de $504 \mathrm{~m}^{2}$. A compactação foi realizada de acordo com os tratamentos $\left(\mathrm{C}_{0}, \mathrm{C}_{1}, \mathrm{C}_{3}, \mathrm{C}_{6}\right.$ e $\left.\mathrm{C}_{11}\right)$ por meio da passagem sequencial dos rodados do trator, perfazendo toda a superfície da parcela, de forma que os pneus comprimissem áreas paralelas entre si (VALADÃO et al., 2015). No momento do tráfego a umidade média solo na camada de 0,00 a $0,20 \mathrm{~m}$ foi de $0,3 \mathrm{~cm}^{3} \mathrm{~cm}^{-3}$ correspondendo a aproximadamente $85 \%$ da capacidade de campo.

A área utilizada vinha sendo submetida ao sistema de cultivo soja-milho sem revolvimento nos últimos seis anos, tendo sido feito uma calagem em superfície há 03 anos com $1000 \mathrm{~kg}$ de calcário dolomítico. Assim, inicialmente, foi realizado o preparo do solo com uma escarificação e gradagem niveladora, visando deixar o solo mais desestruturado para a implantação das compactações. Após a passagem de cada equipamento determinou-se a profundidade de trabalho. No caso do escarificador foi verificado mobilização uniforme até $0,30 \mathrm{~m}$ de profundidade. No caso da grade seu objetivo foi apenas a quebra superficial dos agregados formados durante a escarificação, sendo assim, seu efeito ficou nos primeiros 0,10 $\mathrm{m}$ de profundidade.

As instalações dos tratamentos foram realizadas após as primeiras chuvas da safra agrícola 2016-2017, utilizando um trator MF 292 (105 cv) com rodado de pneus diagonais e massa total de $5 \mathrm{Mg}$, com pressão de insuflagem de $96 \mathrm{kPa}$ nos pneus dianteiros (14.9-24 R1) e $110 \mathrm{kPa}$ nos pneus traseiros (19.4-34 R1), sendo 39\% da massa do trator distribuída no eixo dianteiro e $61 \%$ no eixo traseiro. Após a indução das compactações, foi realizada semeadura a 
lanço de milheto como planta de cobertura, visando à produção de palhada para a proteção do solo no período chuvoso. No final de fevereiro de 2017 realizou-se a dessecação com herbicida não seletivo e a semeadura do feijão-de-porco. Na semeadura do feijão-de-porco utilizou-se o espaçamento de $0,45 \mathrm{~m}$ entre linhas e cinco sementes metro linear a uma profundidade de semeadura de $0,03 \mathrm{~m}$ de forma manual. Para a deposição das sementes foram abertos orifícios com auxílio de uma alavanca pontiaguda, de acordo com o espaçamento e profundidade pré-estabelecidos. Não foi feito nenhum controle de plantas invasoras, insetos pragas e doenças por não ter sido identificado a necessidade em monitoramentos diários realizados na área.

No período de pleno florescimento (70 dias após a emergência) foram coletadas amostras de solo com estrutura preservada utilizando um anel volumétrico de $100 \mathrm{~cm}^{3}$ acoplado a um amostrador do tipo Kopeck, em quatro profundidades (0,0-0,05, 0,05-0,10, 0,10-0,15 e 0,15-0,20 m). Para a obtenção da média da parcela foram coletadas duas amostras em cada profundidade. Nessas amostras foram avaliadas as propriedades físicas: densidade do solo (método do anel volumétrico), porosidade total, macro e microporosidade (método da mesa de tensão a 0,6 MCA) (TEIXEIRA et al., 2017).

O diâmetro radicular e área das raízes foram avaliados em cada parcela, abrindo-se uma trincheira transversal a uma linha de cultivo, conforme Valadão et al. (2015) utilizando fotografia das raízes e analisando as imagens no programa computacional Safira (JORGE; SILVA, 2010).

No período de florescimento foram avaliadas também as seguintes variáveis: massa seca da parte aérea, altura de plantas e teor e conteúdo de N. A altura de plantas foi determinada medindo com uma régua do solo até a ponta do ramo mais alto em 3 plantas escolhidas de forma aleatória por parcela. Para a determinação da massa seca da parte aérea foram coletadas plantas contidas em 2,0 m lineares de cada parcela experimental, em seguida, o material foi levado a estufa de ventilação forçada (temperatura de $65^{\circ} \mathrm{C}$ ) até massa constante. Foi coletado ainda mais duas plantas por parcela para a determinação do teor de N. Para a coleta dessas plantas foram abertos sulcos no entorno das plantas de forma a facilitar a coleta do sistema radicular o mais integro possível, na sequencia as raízes foram lavadas de forma a retirar todo o excesso de solo. Folhas, ramos e raízes foram lavados e secos em estufa de ventilação forçada (temperatura de $65^{\circ} \mathrm{C}$ ), até atingir massa constante. Em seguida o material foi triturado e determinou-se o teor e conteúdo de $\mathrm{N}$ na parte aérea e raízes utilizando a metodologia de digestão sulfúrica seguida de destilação Kjeldahl (TEIXEIRA et al., 2017).

A taxa de cobertura do solo foi realizada pelo método fotográfico utilizando um quadrado metálico com dimensões de $0,5 \times 0,5 \mathrm{~m}$ colocado aleatoriamente dentro de cada parcela. As fotografias foram efetuadas a partir dos 12 dias após a emergência (DAE) utilizando uma câmera digital, sendo fotografadas uma vez por semana até a cobertura completa do solo aos 54 DAE. Posteriormente, com auxílio do programa Microsoft Power Point, foi inserido um quadriculado com 900 pontos para determinar a taxa de cobertura do solo utilizando a escala percentual, onde foi feita a quantificação dos pontos que coincidiram com as plantas de cobertura, conforme a metodologia adaptada de Sodré Filho et al. (2004). 
Os resultados foram submetidos à análise de variância e, quando significativo pelo teste $\mathrm{F}(\mathrm{p} \leq 0,05)$, foi aplicada análise de regressão para o número de passadas do trator em função da profundidade do solo para as variáveis de solo e DAE para taxa de cobertura, utilizando o programa estatístico SISVAR (FERREIRA, 2014). Para a análise de regressão foi utilizado a média das repetições de cada tratamento e para a escolha do modelo adotou-se a significância do teste $\mathrm{F}$ na análise de variância (ANOVA), significância dos parâmetros pelo teste $\mathrm{t}$ e finalmente o coeficiente de determinação do modelo.

\section{RESULTADOS E DISCUSSÃO}

\section{Propriedades físicas do solo e sistema radicular}

A análise de variância das propriedades físicas do solo e do sistema radicular da cultura é apresentado na Tabela 2. As propriedades físicas do solo foram alteradas pelo trânsito do trator, porém, não de maneira uniforme em todas as profundidades avaliadas. A macroporosidade e a microporosidade não foram alteradas na camada de $0,10-0,15 \mathrm{~m}$. A porosidade total e a densidade do solo não sofreram alterações na camada de 0,0-0,05 m. A área da raiz não sofreu alterações na camada de $0,15-0,20 \mathrm{~m}$. O diâmetro das raízes não sofreu alterações pela compactação. De modo geral, a camada de 0,05-0,10 foi a que apresentou maior número de variáveis com alterações, mostrando sua susceptibilidade a compactação.

Tabela 2. Valores de F, significância, coeficiente de variação das propriedades físicas do solo e características do sistema radicular, analisados nas diferentes profundidades em função da compactação do solo na cultura do feijão-de-porco. F values, significance, coefficient of variation of the physical properties of the soil and characteristics of the root system, analyzed at different depths as a function of soil compaction in the culture of jack bean.

\begin{tabular}{ccccccccc}
\hline \multirow{2}{*}{ Variáveis } & \multicolumn{7}{c}{ Profundidade $(\mathrm{m})$} \\
\cline { 2 - 9 } & \multicolumn{2}{c}{$0,0-0,05$} & \multicolumn{7}{c}{$0,05-0,10$} & $0,10-0,15$ & \multicolumn{2}{c}{$0,15-0,20$} \\
\cline { 2 - 9 } & $\mathrm{F}$ & $\mathrm{CV}$ & $\mathrm{F}$ & $\mathrm{CV}$ & $\mathrm{F}$ & $\mathrm{CV}$ & $\mathrm{F}$ & $\mathrm{CV}$ \\
\hline Ma & $3,19^{*}$ & 33,40 & $29,03^{* *}$ & 14,41 & $2,57^{\text {ns }}$ & 33,42 & $36,59^{* *}$ & 10,84 \\
Mi & $8,50^{* *}$ & 6,09 & $5,58^{* *}$ & 4,11 & $1,60^{\text {ns }}$ & 7,94 & $16,43^{* *}$ & 6,64 \\
PT & $1,37^{\text {ns }}$ & 7,93 & $23,48^{* *}$ & 3,97 & $5,36^{* *}$ & 10,54 & $14,39^{* *}$ & 4,79 \\
Ds & $1,38^{\text {ns }}$ & 7,55 & $23,48^{* *}$ & 3,22 & $5,36^{* *}$ & 8,38 & $14,38^{* *}$ & 4,28 \\
AR & $5,68^{* *}$ & 28,92 & $5,40^{*}$ & 39,53 & $4,75^{*}$ & 25,76 & $1,56^{\text {ns }}$ & 38,44 \\
DR & $0,90^{\text {ns }}$ & 27,22 & $0,27^{\text {ns }}$ & 41,76 & $0,78^{\text {ns }}$ & 73,93 & $0,78^{\text {ns }}$ & 39,84 \\
\hline
\end{tabular}

Nota: **Significativo a $\mathrm{p} \leq 0,01 ; *$ Significativo a $\mathrm{p} \leq 0,05 ;{ }^{\text {ns }} \mathrm{Não}$ significativo a $\mathrm{p} \leq 0,05 ; \mathrm{CV}=$ coeficiente de variação em \%; $\mathrm{Ma}=$ Macroporosidade; $\mathrm{Mi}=$ Microporosidade; $\mathrm{PT}=$ Porosidade total; $\mathrm{Ds}=$ Densidade do solo; $\mathrm{AR}=$ Área radicular; DR $=$ Diâmetro radicular. ${ }^{* *}$ Significant at $p \leq 0.01 ; *$ Significant at $p \leq 0.05$; ns Not significant at $p \leq 0.05 ; C V=$ coefficient of variation in\%; $M a=$ Macroporosity; $M i=$ Microporosity; $P T=$ Total porosity; $D s=$ Soil density; $A R=$ Root area $; R=$ Root diameter .

Fonte: Autoria própria. Own authorship.

A Ma apresentou redução de 34, 52, 50 e 53 nas camadas de 0,0-0,05, 0,05-0,10 e 0,15$0,20 \mathrm{~m}$, respectivamente, quando comparado os tratamentos $\mathrm{C}_{0}$ e $\mathrm{C}_{11}$ (Figura 2A). A maior redução foi apresentada na camada de $0,15-0,20 \mathrm{~m}$ saindo de $0,3 \mathrm{~m}^{3} \mathrm{~m}^{-3}$ em $\mathrm{C}_{0}$ para $0,2 \mathrm{~m}^{3}$ $\mathrm{m}^{-3}$ em $\mathrm{C}_{11}$. Já para Mi houve um aumento de 20,8, 12,1, 10,7 e 39,1\%, nas camadas de 0,0- 
0,05, 0,05-0,10 e 0,15-0,20 m, respectivamente, quando comparado os tratamentos $\mathrm{C}_{0}$ e $\mathrm{C}_{11}$, para a camada de maior alteração $0,15-0,20 \mathrm{~m}$, valores variam de $\mathrm{C}_{0} 0,20$ para $0,3 \mathrm{~m}^{3} \mathrm{~m}^{-3} \mathrm{em}$ $\mathrm{C}_{11}$ (Figura 2B). Fazendo a mesma comparação com a camada de 0,10-0,15 m, mesmo que não sendo significativo, foi possível observar que a Ma apresentou redução de $50 \%$ e para Mi um aumento de $11 \%$, quando comparado os tratamentos $\mathrm{C}_{0}$ e $\mathrm{C}_{11}$.

A compactação ocasionada pelo tráfego de máquinas deixa o solo sujeito à redução da continuidade dos poros, ou seja, quando a Ma e Mi são alteradas e como essas variáveis fazem parte da composição da PT e também pode apresentar alterações (PAGLIAI et al., 2003). Sendo assim, a PT (Figura 2C) apresentou redução de 20, 24 e 18\%, nas camadas de 0,05-0,10, 0,10-0,15 e 0,15-0,20 m, respectivamente, quando comparados os tratamentos $\mathrm{C} 0 \mathrm{e}$ C11.

Como as variáveis estão relacionadas, ao contrário do ocorrido com a PT a Ds teve um aumento de acordo com os tratamentos (Figura 2D), o que vem corroborar ainda mais a compactação do solo ocasionada pelo tráfego do trator agrícola. Para a Ds o aumento foi de 20, 26 e $21 \%$ nas camadas de $0,05-0,10 ; 0,10-0,15$ e $0,15-0,20 \mathrm{~m}$, respectivamente, quando comparados os tratamentos da $\mathrm{C} 0$ e $\mathrm{C} 11$.

O fato de a PT e Ds não terem apresentado alterações na camada superficial pode estar relacionado à plasticidade encontrada no solo, fazendo com que o solo se desloque lentamente de acordo com a pressão aplicada pelos pneus do trator e do conteúdo de água (capacidade de campo) (MACHADO et al., 2005).

Uma atenção especial deve ser dada à camada de $0,10-0,15 \mathrm{~m}$, pois para PT o menor valor apresentado foi de $0,4 \mathrm{~m}^{3} \mathrm{~m}^{-3}$, já para Ds o maior valor foi de $1,5 \mathrm{Mg} \mathrm{m}^{-3}$, para ambas no tratamento $\mathrm{C} 11$. Esses valores mostraram formação de compactação subsuperficial. Resultados semelhantes foram encontrados por Valadão et al. (2015) e Scapinelli et al. (2016) no mesmo solo estudado. Já Oliveira et al. (2012) encontraram valores inferiores de Ds em um Latossolo Vermelho Eutroférrico típico, apresentando compactação na camada mais superficial. Mostrando que a relação entre o trator, tipo do pneu, a pressão de inflação do pneu e o conteúdo de água no solo influenciam a formação da camada compactada (CORTEZ et al., 2014) e quanto maior a pressão do pneu mais subsuperficial será a compactação (MACHADO et al., 2005), provavelmente, por ocasionar menor área de contato possibilitando maiores pressões de maneira mais localizada.

Em condições naturais de solo (C0) as características do perfil eram: $\mathrm{Ma} 0,2 \mathrm{~m}^{3} \mathrm{~m}^{-3}$, Mi $0,3 \mathrm{~m}^{3} \mathrm{~m}^{-3}$, PT $0,5 \mathrm{~m}^{3} \mathrm{~m}^{-3}$, Ds $1,2 \mathrm{Mg} \mathrm{m}^{-3}$ (médias do perfil). Essas características estão próximas das ideais, propostas por Malavolta (2006), em que aproximadamente 50\% do solo, em volume devem ser constituídos por espaços vazios igualmente ocupados por água (microporos) e ar (macroporos). Com o tráfego do trator, a pressão exercida pelo pneu promoveu um rearranjo das partículas sólidas, diminuindo o diâmetro dos poros, obstruindo os espaços vazios entre agregados e transformando os macroporos em microporos (SCAPINELLI et al., 2016). Nesse contexto, a compressão do solo resultou no aumento da Ds e da Mi e na diminuição da Pt e da Mac, chegando aos valores máximos em C11 de Ma 0,1 $\mathrm{m}^{3} \mathrm{~m}^{-3}$ e Mi $0,3 \mathrm{~m}^{3} \mathrm{~m}^{-3}$, PT $0,4 \mathrm{~m}^{3} \mathrm{~m}^{-3}$, Ds $1,4 \mathrm{Mg} \mathrm{m}^{-3}$ (médias do perfil). Portanto, os valores encontrados neste trabalho, quando observados os valores no tratamento $\mathrm{C} 11$, estão 
acima do nível considerado crítico de Ma em $0,10 \mathrm{~m}^{3} \mathrm{~m}^{-3}$ para o desenvolvimento das raízes estabelecido por Pagliai et al. (2003), e inferior ao limite crítico para o desenvolvimento de plantas de cobertura considerado por Lima et al (2015) de Ds até 1,7 $\mathrm{Mg} \mathrm{m}^{-3}$ para solos com características texturais próximas ao do trabalho.

(A)

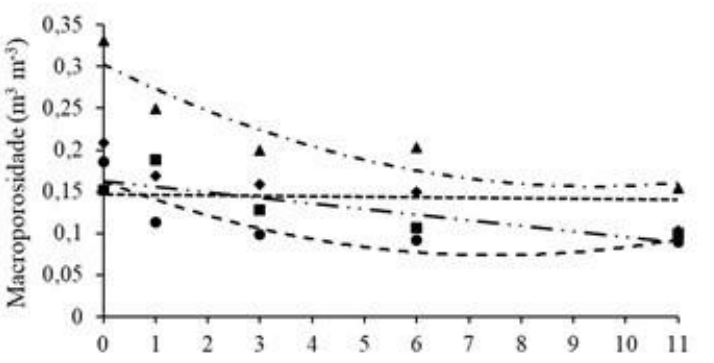

(B)

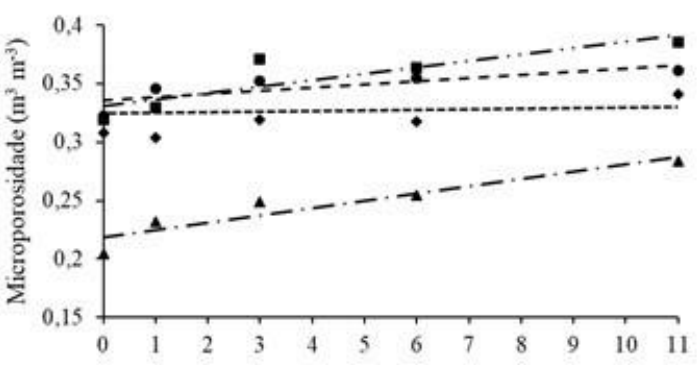

(C)

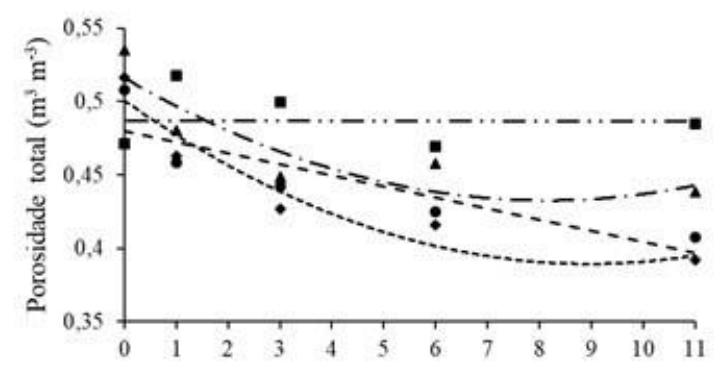

(D)

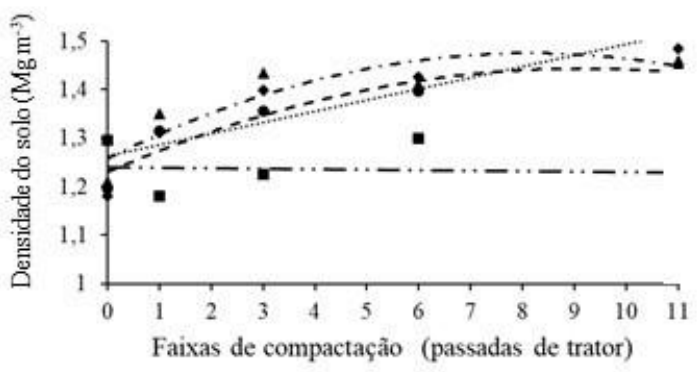

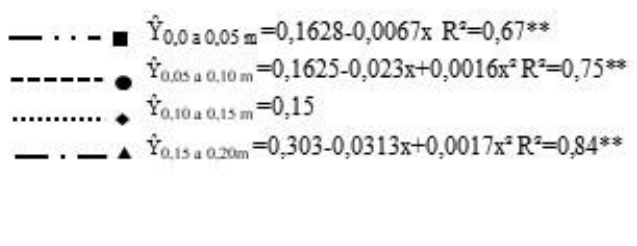
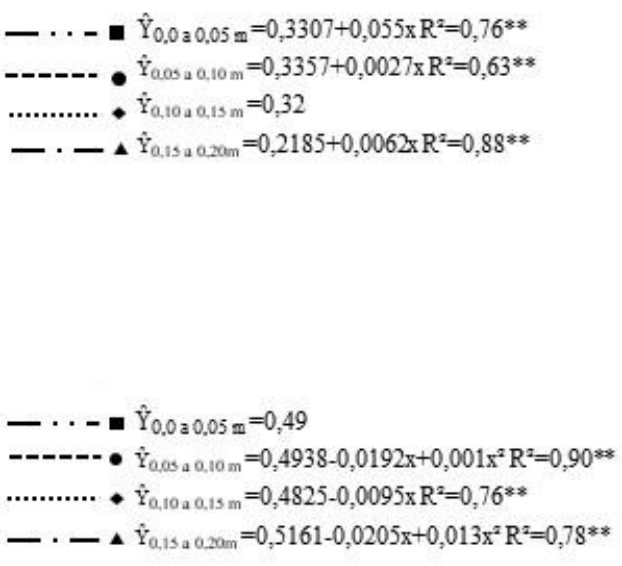

- - - $\hat{\mathrm{Y}}_{0,0 \mathrm{a} 0,05 \mathrm{~m}}=1,25$

- - $\hat{\mathrm{Y}}_{0,05 \mathrm{~S} 0,10 \mathrm{~m}}=1,2301+0,0466 \mathrm{x}-0,0025 \mathrm{x}^{2} \mathrm{R}^{2}=0,90^{* *}$ - $\hat{Y}_{0,10 a} 0.15 \mathrm{~m}=1,2626+0,0232 \times \mathrm{R}^{2}=0,76^{* *}$

- - - $\hat{\mathrm{Y}}_{0,15 \mathrm{a} 0,20 \mathrm{~m}}=1,2581+0,0533-0,0033 \mathrm{x}^{2} \mathrm{R}^{2}=0,78^{* *}$

Figura 2. Propriedades físicas do solo nas diferentes profundidades em função do número de passadas do trator. Physical properties of the soil at different depths depending on the number of passes of the tractor.

Fonte: Autoria própria. Own authorship.

Quanto ao sistema radicular, a compactação alterou a área das raízes do feijão-de-porco entre as camadas de 0,0-0,15 m de profundidade (Figura 3). Quando comparados os valores da em cada profundidade do tratamento $\mathrm{C}_{0}$ com os demais, foi observado que na camada de 0,0-0,05 m os tratamentos $C_{1}$ e $C_{3}$ apresentaram aumento de área em 74,4 e 48,6\%. Já os tratamentos $\mathrm{C}_{6}$ e $\mathrm{C}_{11}$ apresentaram redução de 13,5 e 17,2\%, respectivamente. Os maiores valores de aumento da área da raiz foram encontrados na profundidade de 0,05-0,10 $\mathrm{m}$, onde $54,0,138,6$ e 12,2\% nos tratamentos $\mathrm{C}_{1}, \mathrm{C}_{3}$ e $\mathrm{C}_{6}$, respectivamente. Porém, $\mathrm{C}_{11}$ na mesma 
profundidade apresentou redução de 19,2\%. Na camada de 0,10-0,15 m, independente do tratamento, houve redução na área das raízes.

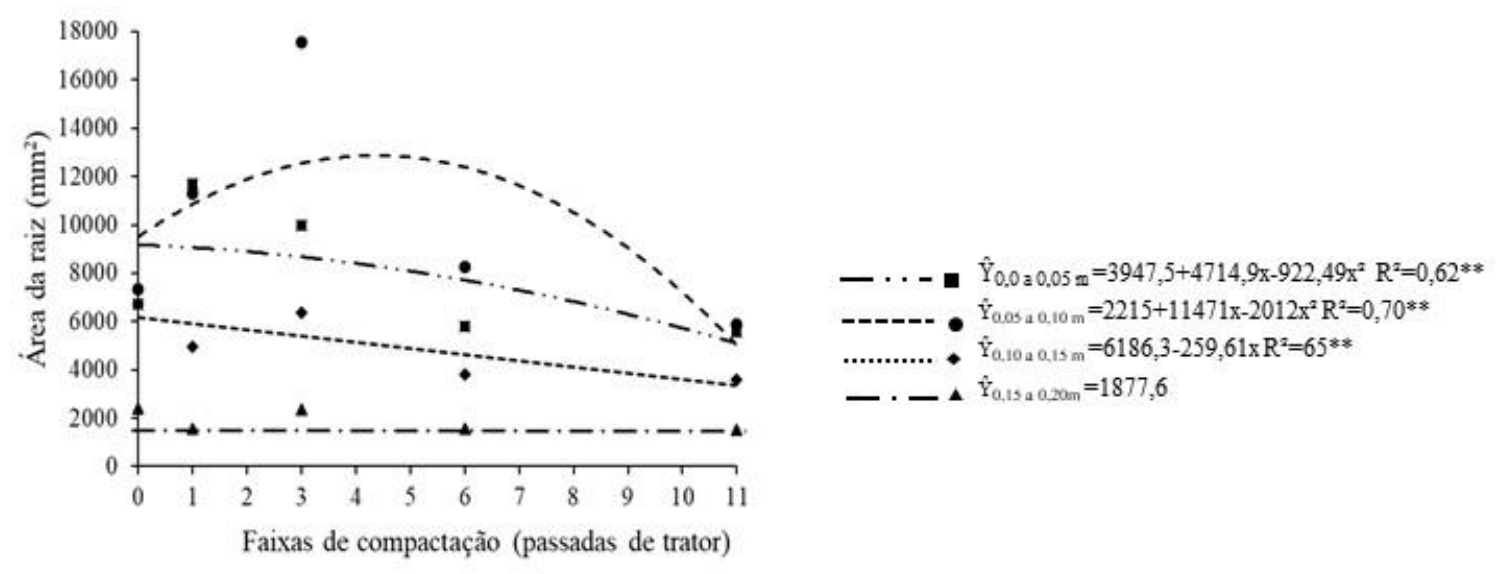

Figura 3. Área da raiz nas diferentes camadas de profundidade em função da compactação do solo na cultura do feijão-de-porco. Root area in the different depth as a function of soil compaction in the jack bean plant.

Fonte: Autoria própria. Own authorship.

Ao analisar a distribuição do sistema radicular no perfil do solo, a compactação promoveu alterações (Figura 4). A cultura apresentou crescimento radicular vigoroso e profundo, apesar de apresentarem muitas ramificações das raízes laterais nas camadas mais superficiais, as quais apresentou grande fragilidade durante a abertura da trincheira para a coleta de plantas. A raiz pivotante atingiu as maiores profundidades, assim como observado por Reinert et al. (2008), que não encontraram restrições severas para o crescimento radicular do feijão-de-porco quando submetido à compactação em um Argissolo Vermelho. Quando comparadas aos valores da área de raiz no perfil de cada tratamento, pode ser observado que $31,7,38,3,48,4,42,5$ e $35,6 \%$ nos tratamentos $\mathrm{C}_{0}, \mathrm{C}_{1}, \mathrm{C}_{3}, \mathrm{C}_{6}$ e $\mathrm{C}_{11}$, respectivamente, se encontram na camada de 0,05-0,010 m, sendo a camada com as maiores concentrações de raízes.

Os resultados na literatura variam de acordo com a cultura estudada. Scapinelli et al. (2016) em solo descompactado na cultura do girassol (Helianthus annus L.) mostraram que 93,0\% das raízes estavam nos primeiros $0,10 \mathrm{~m}$ de profundidade. Já Valadão et al. (2015) na cultura da soja (Glycine max L.), em solos sem adição de passagem de trator observaram que $45,0 \%$ das raízes se concentravam até $0,05 \mathrm{~m}$, enquanto em 2, 4 e 8 passadas de trator 59,7 e $75,0 \%$ das raízes se concentravam até essa profundidade, e 53,7\% das raízes do milho (Zea mays L.) encontravam-se na camada de 0,0-0,10 m, também observaram redução de $23 \%$ da área de raiz da soja na camada de 0,0-0,05 m em comparação de sem compactação com oito passadas de trator. Oliveira et al. (2012) não observaram alteração na área de raízes de acordo com os níveis de compactação na cultura da soja.

Apesar de a área das raízes apresentar redução com a compactação, a variável diâmetro de raiz não sofreu alterações significativas pela compactação (Tabela 2). A resistência do solo à penetração pode interferir no crescimento radicular, porém o estresse hídrico é o principal fator nessa alteração, quando ocorre a perda do turgor pode ser acompanhada a diminuição do diâmetro das raízes em até $50 \%$, e quando o turgor é restabelecido pode ser ter aumento de 20 
a 50\% do diâmetro (HUCK et al., 1970), mostrando que a resposta da planta à compactação pode ser dependente da disponibilidade hídrica. Camargo; Alleoni (1997) relataram que a pressão de crescimento das raízes depende da pressão de turgor das células do meristema radicular em processo de alongamento, e da área de contato das raízes sobre um agente rígido externo, assim, quanto maior o diâmetro da raiz, maior é a força exercida no processo de alongamento das células do meristema radicular para penetração em determinada camada de solo. O que pode explicar os dados encontrados nesse trabalho, pois a cultura apresenta grandes ramificações das raízes laterais, que são mais finas, e houve veranicos durante o período em que a cultura ficou no campo, pela semeadura no final do período chuvoso.

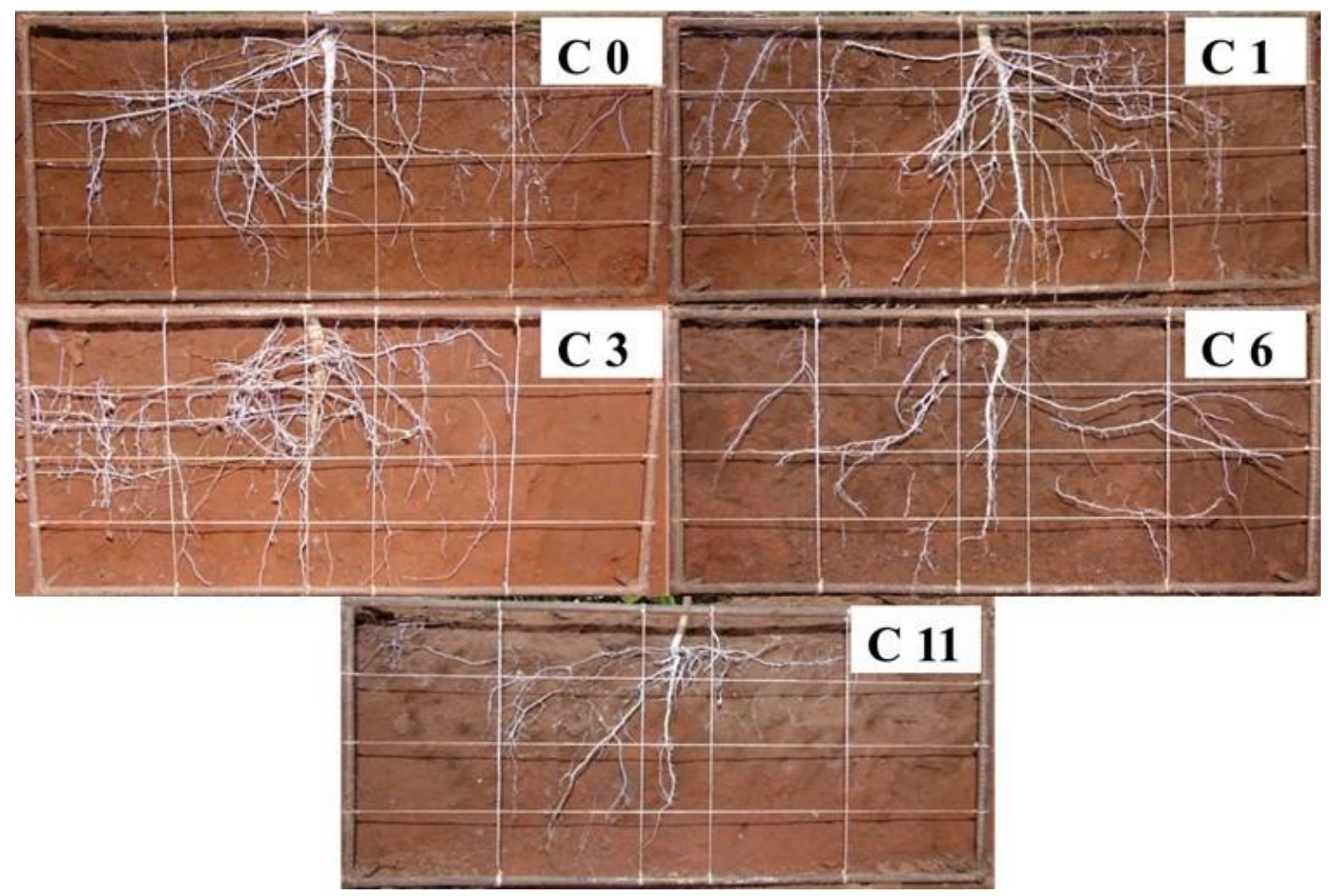

Figura 4. Distribuição das raízes do feijão-de-porco, em função da compactação do solo com zero $\left(\mathrm{C}_{0}\right)$, uma $\left(\mathrm{C}_{1}\right)$, três $\left(\mathrm{C}_{3}\right)$, seis $\left(\mathrm{C}_{6}\right)$ e onze $\left(\mathrm{C}_{11}\right)$ passadas de trator. Distribution of jack bean roots, according to soil compaction with zero $(C 0)$, one $\left(C_{1}\right)$, three $\left(C_{3}\right)$, six $\left(C_{6}\right)$, and eleven $\left(C_{11}\right)$ passed by tractor.

Fonte: Autoria própria.Own authorship.

De acordo com Foloni et al. (2006), plantas de cobertura antecedendo a cultura da soja em solos compactados, as espécies que apresentaram melhor desempenho de crescimento radicular dentro da camada compactada, de maneira geral foram as que tiveram menor diâmetro médio de raízes. No sistema radicular do girassol, quando em solo compactado, o diâmetro sofreu alteração apena na camada de 0,05-0,10 m (SCAPINELLI et al., 2016). Na cultura da soja Valadão et al. (2015) observaram aumento no diâmetro de 122,9\% na faixa de compactação com oito passadas de trator comparado com zero passadas de trator. 


\section{Parte aérea do feijão-de-porco}

O crescimento e desenvolvimento da parte aérea da planta é pode sofrer interferência das condições a que o sistema radicular está submetido. Assim, os resultados obtidos na análise de variância paras as variáveis massa seca da parte aérea, teor de nitrogênio e conteúdo de nitrogênio para na parte aérea e raiz, e altura de planta, encontram-se Tabela 3. As variáveis de $\mathrm{N}$ na parte aérea, altura de planta, massa seca da parte aérea não sofreram alterações com a compactação.

Tabela 3. Valores de F, significância, coeficiente de variação e médias das variáveis de planta em função da compactação do solo sob a cultura do feijão-de-porco. $F$ values, significance, coefficient of variation and means of plant variables as a function of soil compaction under the jack bean plant.

\begin{tabular}{cccc}
\hline Variáveis & $\mathrm{F}$ & $\mathrm{CV}$ & Média \\
\hline MSPA $(\mathrm{g}$ por planta) & $0,21^{\mathrm{ns}}$ & 21,83 & 100,0 \\
$\mathrm{TNr}\left(\mathrm{g} \mathrm{kg}^{-1}\right)$ & $59,16^{* *}$ & 7,60 & 24,1 \\
$\mathrm{CNr}\left(\mathrm{kg} \mathrm{ha}^{-1}\right)$ & $15,06^{* *}$ & 19,96 & 15,1 \\
$\mathrm{TNpa}\left(\mathrm{g} \mathrm{kg}^{-1}\right)$ & $0,75^{\mathrm{ns}}$ & 20,33 & 45,2 \\
$\mathrm{CNpa}\left(\mathrm{kg} \mathrm{ha}^{-1}\right)$ & $0,65^{\mathrm{ns}}$ & 29,81 & 502,1 \\
$\mathrm{Ap}(\mathrm{m})$ & $1,22^{\mathrm{ns}}$ & 10,33 & 1,2 \\
\hline
\end{tabular}

Nota: **Significativo a $\mathrm{p} \leq 0,01 ; *$ Significativo a $\mathrm{p} \leq 0,05 ;{ }^{\text {ns }}$ Não significativo a $\mathrm{p} \leq 0,05 ; \mathrm{CV}=$ coeficiente de variação em \%; MSPA = Massa seca da parte aérea; $\mathrm{TNr}=$ Teor de nitrogênio na raiz; $\mathrm{CNr}=$ Conteúdo de Nitrogênio na raiz; TNpa = Teor de nitrogênio da parte aérea; $\mathrm{CNpa}=$ Conteúdo de Nitrogênio da parte aérea; $\mathrm{Ap}=$ Altura da planta. $* *$ Significant at $p \leq 0.01 ; *$ Significant at $p \leq 0.05 ; n$ s Not significant at $p \leq 0.05 ; C V=$ coefficient of variation in $\%$; DMAP = Dry mass of the aerial part ;; TNr = nitrogen content in the root; $\mathrm{CNr}=$ Nitrogen content at the root; $T N p a=$ Nitrogen content of the aerial part; $C N p a=$ Nitrogen content of the aerial part; $A p=$ Height of the plant.

Fonte: Autoria própria. Own authorship.

A MSPA não apresentou alterações em função das alterações ocorridas no solo pela passagem do trator, resultado semelhante ao encontrado por Foloni et al. (2006), em Nitossolo Vermelho de textura argilosa onde a produção de massa seca da parte aérea dos adubos verdes feijão guandu, Crotalária juncea e guandu anão (Cajanus cajan), não foi prejudicada pela compactação do solo em subsuperfície. Já Farias et al. (2013), observaram que o feijão guandu anão, cultivado em Latossolo Vermelho apresentou redução de 76,1\% na massa seca da parte aérea do menor para o maior nível de compactação do solo a uma densidade do solo de 1,0 para $1,8 \mathrm{Mg} \mathrm{m}^{-3}$.

Os valores de Mspa divergem dos encontrados na literatura, pois, os encontrados neste trabalho foram bem superiores. Quando convertidos os valores, foi encontrado para a parte aérea uma massa seca média de, aproximadamente, $11,1 \mathrm{Mg} \mathrm{ha}^{-1}$. Teodoro et al., (2011) utilizando 10 plantas por metro linear em um Latossolo Vermelho-Amarelo distrófico, encontraram de $8,8 \mathrm{Mg} \mathrm{ha}^{-1}$ de massa seca para o feijão-de-porco no período do florescimento. Padovan et al. (2011), trabalhando em dois solos, sendo um Latossolo Vermelho Distroférrico e um Latossolo Vermelho Distrófico típico, aos 117 e 112 DAE encontraram valores de 7,7 e 4,6 $\mathrm{Mg} \mathrm{ha}^{-1}$, respectivamente, mostrando que as condições edafoclimáticas interferiram no acúmulo de massa seca. 
As variáveis teor de $\mathrm{N}$ nas raízes e conteúdo $\mathrm{N}$ total nas raízes, sofreram alterações em seu valor com a compactação (Figura 5). Para o teor de nitrogênio raiz foi observado um aumento de 58,4, 85,7, 118,2 e 130,6\% para os tratamentos $\mathrm{C}_{1}, \mathrm{C}_{3}, \mathrm{C}_{6}$ e $\mathrm{C}_{11}$, respectivamente, quando comparados com $\mathrm{C}_{0}$. Já para nitrogênio total na raiz utilizando a mesma comparação com C0, para os outros tratamentos $\mathrm{C}_{1}, \mathrm{C}_{3}, \mathrm{C}_{6}$ e $\mathrm{C}_{11}$ o aumento foi de 128,9, 129,1, 210,2 e $59,3 \%$, respectivamente.

(A)

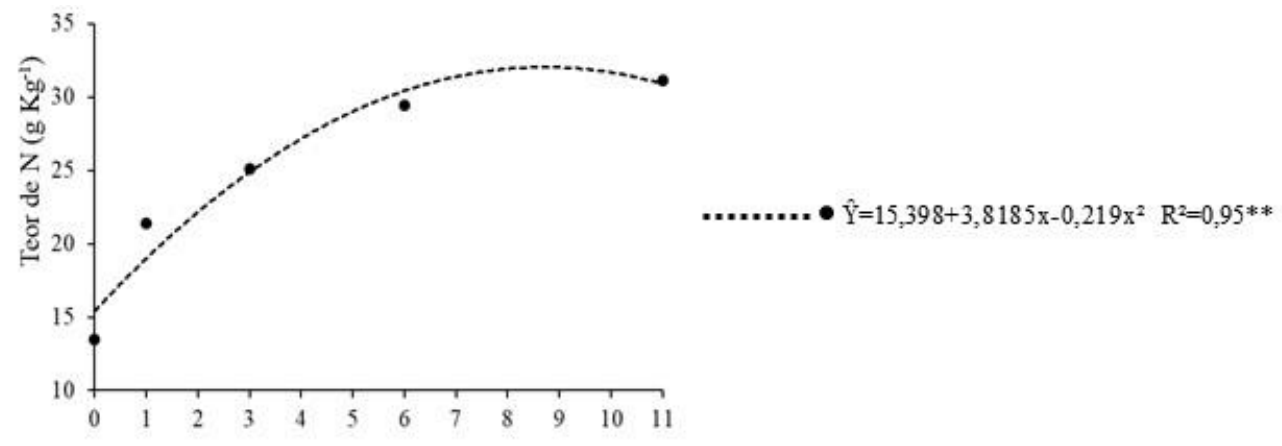

(B)

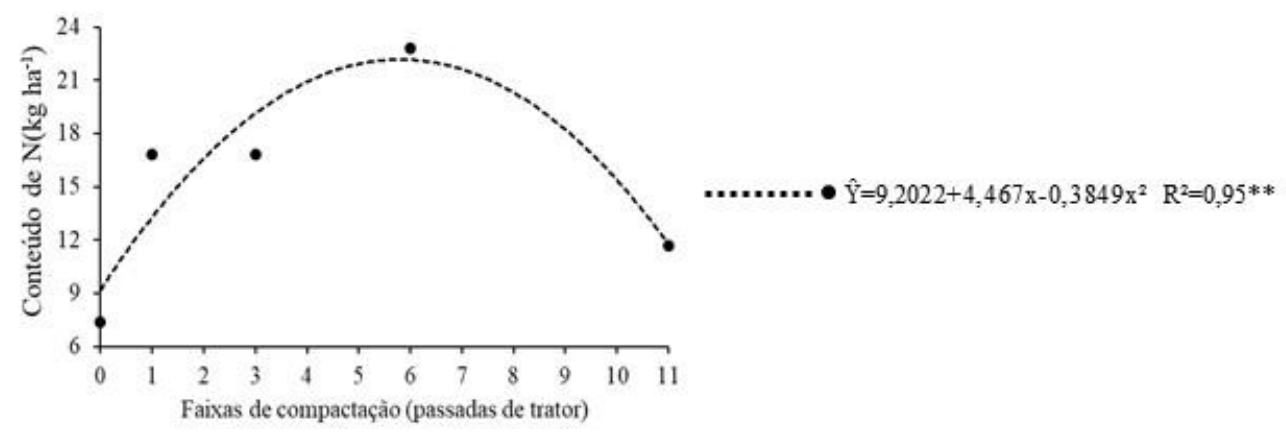

Figura 5. Teor de $\mathrm{N}$ nas raízes (A) e conteúdo de $\mathrm{N}$ nas raízes (B) em função da compactação do solo na cultura do feijão-de-porco. Nitrogen content in the root $(A)$ and nitrogen content in the root $(B)$ as a function of soil compaction in the jack bean plant.

Fonte: Autoria própria. Own authorship.

Os altos valores de $\mathrm{N}$ encontrados podem estar relacionados a fixação biológica de nitrogênio (FBN), já que os dados de $\mathrm{N}$ foram obtidos da massa seca das raízes, que no momento da coleta da amostra ainda continha nódulos ativos, que podem conter alta concentração de $\mathrm{N}$. Uma explicação para a variação do teor e conteúdo de $\mathrm{N}$ nas raízes quando em compactação, é que segundo Farias et al. (2013), a quantidade de massa seca de raiz está envolvida com essa associação, quanto mais massa seca possivelmente maior será a colonização, porém, as condições de menor macroporosidade podem causar alterações drásticas nos processos dinâmicos e biológicos do solo. Sendo encontrado essa alteração drástica dessa associação no tratamento $\mathrm{C}_{11}$, podendo ser observado redução da massa seca da raiz e consequentemente do conteúdo de N. Malavolta (2006) relata que a FBN para o feijãode-porco é aproximadamente $12-48 \mathrm{~kg} \mathrm{ha}^{-1}$ de $\mathrm{N}$, e que essa simbiose se encerra próximo ao florescimento.

Apesar de teor e conteúdo de $\mathrm{N}$ na parte aérea não apresentar alterações pela compactação, pode se observar que o valor de média feito de todos os tratamentos para o teor e conteúdo de $\mathrm{N}$ foi de 45,2 $\mathrm{g} \mathrm{kg}^{-1}$ e 502,1 $\mathrm{kg} \mathrm{ha}^{-1}$, respectivamente. Esses valores foram bem superiores ao encontrado na literatura, como relatado por Leal et al. (2013), que encontraram 
teores de $\mathrm{N}$ para crotalária (Crotalaria juncea) de 25,6 e para o milheto de $12,1 \mathrm{~g} \mathrm{~kg}^{-1}$, já Padovan et al. (2011), em um Latossolo Vermelho Distroférrico, aos 105 DAE do feijão-deporco, obtiveram de 212,2 $\mathrm{kg} \mathrm{ha}^{-1}$ do conteúdo de $\mathrm{N}$, e Teodoro et al. (2011) encontraram no período de florescimento $335,6 \mathrm{~kg} \mathrm{ha}^{-1}$ de conteúdo de $\mathrm{N}$ no feijão-de-porco.

O N exerce papel importante no desenvolvimento da planta e, consequentemente, na produção de MSPA por fazer parte da composição das proteínas e ácidos nucléicos, os quais participam ativamente da síntese de compostos orgânicos, que formam a estrutura do vegetal (MALAVOLTA, 2006). O grande acúmulo de $\mathrm{N}$ pode ter auxiliado no desenvolvimento da parte aérea, sendo uma resposta para a não alteração no seu desenvolvimento quando em compactação.

A altura não foi alterada pelos níveis de compactação sendo observado valor médio 1,1 m. Valores superiores aos de Lima et al. (2015), em Latossolo Vermelho de cerrado, cuja maior altura de planta para a Crotalaria ochroleuca foi na densidade se solo de $1,3 \mathrm{Mg} \mathrm{m}^{-3}$ com 0,9 m. Quanto à taxa de cobertura (Tabela 4), não houve significância ao decorrer do crescimento da cultura em função da compactação.

Tabela 4. Valores de F, significância, coeficiente de variação e médias da taxa de cobertura em função da compactação do solo na cultura do feijão-de-porco. F values, significance, coefficient of variation and averages of the coverage rate as a function of soil compaction in the jack bean plant.

\begin{tabular}{cccc}
\hline DAE & F & CV & Média (\%) \\
\hline 12 & $0,824^{\text {ns }}$ & 17,64 & 32,1 \\
19 & $2,113^{\text {ns }}$ & 14,87 & 58,1 \\
26 & $0,633^{\text {ns }}$ & 14,11 & 68,0 \\
33 & $3,236^{\text {ns }}$ & 11,26 & 76,6 \\
40 & $0,297^{\text {ns }}$ & 3,67 & 96,1 \\
47 & $0,336^{\text {ns }}$ & 2,84 & 97,2 \\
\hline
\end{tabular}

Nota: DAE= Dias após a emergência; $\mathrm{CV}=$ coeficiente de variação em \%; ${ }^{\text {ns }}$ Não significativo a $\mathrm{p} \leq 0,05 . D A E=$ Days after the emergency; $C V=$ coefficient of variation in $\%$; ${ }^{n s}$ Not significant at $p \leq 0.05$.

Fonte: Autoria própria. Own authorship.

Observou-se que aos 12 DAE (Figura 6), o feijão-de-porco apresentou uma taxa de cobertura média para todos os tratamentos de 32,1\%, atingindo uma cobertura média de 97,2\% aos 47 DAE. Já aos 54 dias, independente do tratamento, foi observada uma taxa de cobertura de $100 \%$ e não foi mais possível visualizar o quadrado metálico utilizado na análise. Resultado semelhante ao encontrado por Teodoro et al. (2011) que encontraram uma taxa de cobertura para o feijão-de-porco em sistema convencional de $46 \%$ aos 40 DAE, atingindo $100 \%$ de cobertura do solo aos 60 DAE. 


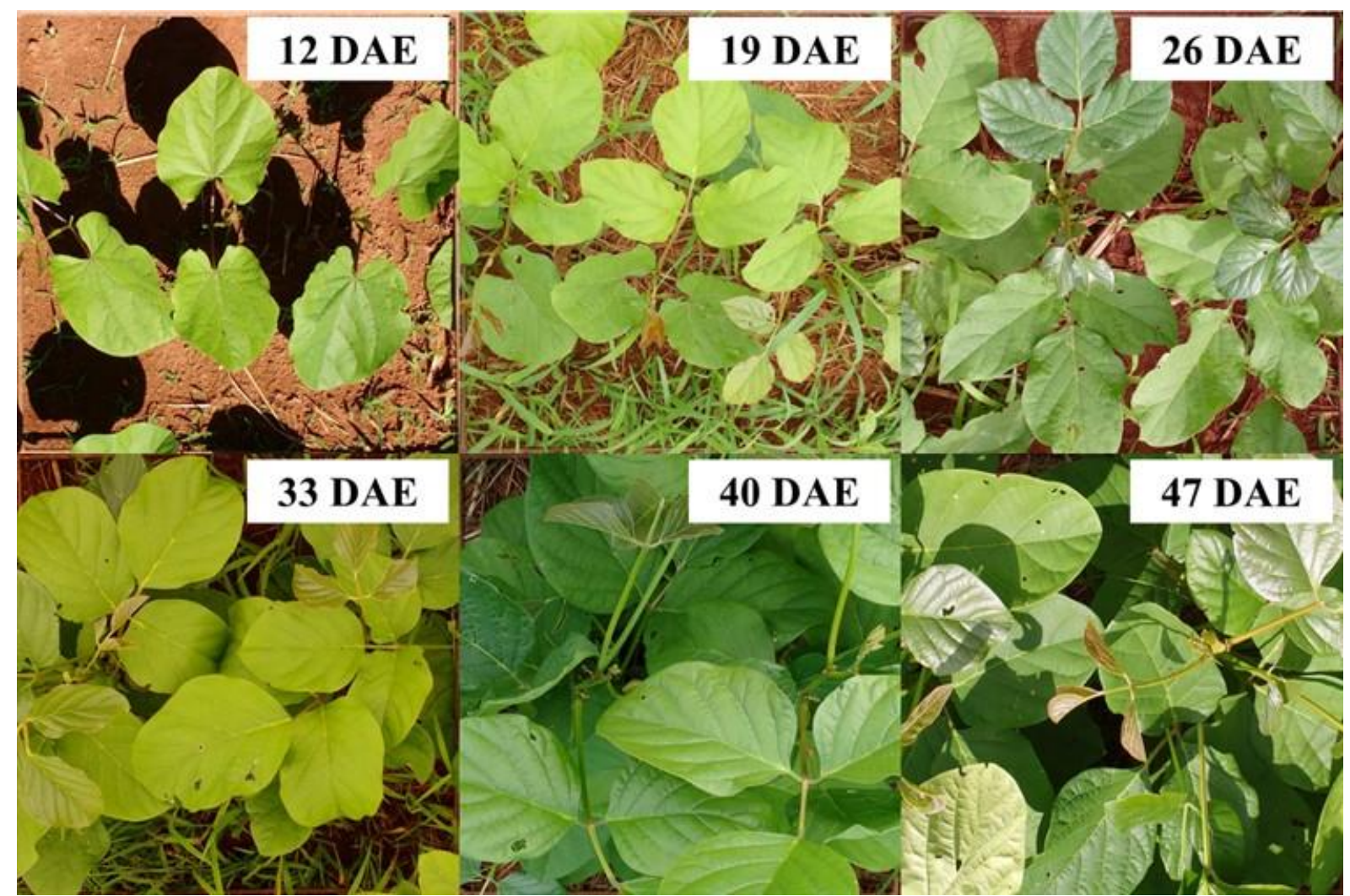

Figura 6. Evolução da cobertura do solo na cultura do feijão-de-porco. Evolution of soil cover in the jack bean crop.

Fonte: Autoria própria. Own authorship.

De modo geral, mesmo em ambiente onde houve alteração do sistema radicular (bem menor que quando comparado com outras culturas em condições semelhantes) isso não foi suficiente para comprometer o desenvolvimento da parte aérea mostrando o potencial da cultura em se estabelecer em condições adversas, podendo ser uma alternativa para a produção de biomassa, cobertura e recuperação de solos que passam por problemas de degradação da estrutura ainda mais por ter a possibilidade de ser inserida na região após a cultura principal por tolerar uma menor disponibilidade hídrica. Ressalta-se ainda, que apesar dos resultados promissores são necessários mais trabalhos visando avaliar os efeitos a longo prazo da adoção do feijão-de-porco em sistema de rotação, principalmente, sobre as propriedades físicas do solo.

\section{CONCLUSÃO}

As mudanças nas propriedades físicas do solo provocam alteração no sistema radicular do feijão-de-porco e na absorção de nitrogênio, porém, não o suficiente para comprometer o desenvolvimento da planta, sendo uma cultura alternativa para rotação de cultura em solos compactados 


\section{REFERÊNCIAS BIBLIOGRÁFICAS}

CAMARGO, O. A.; ALLEONI, L. R. F. Compactação do solo e o desenvolvimento das plantas. Piracicaba: Escola Superior de Agricultura Luiz de Queiroz, 1997. 132 p.

CORTEZ, J. W.; OLSZEVSKI, N.; PIMENTA, A.; PATROCÍNIO FILHO, A. P.; SPUZA, S. B.; NAGANHAMA, H. J. Avaliação da intensidade de tráfego de tratores em alguns atributos físicos de um Argissolo Amarelo. Revista Brasileira de Ciência do Solo, Viçosa, v. 38, n. 1, p.1000-1010, 2014.

DOMIT, L. A.; OKMURA, R. S.; BARBOSA, G. M. C.; HIGASHIBARA, L. R.; DALBOSCO, M.; MARIANO, D. C.; ZORZENONI, T. O.; GUIMARÃES, M. F. Tempo de adoção do sistema plantio direto e a relação com atributos do solo. Revista Agrarian, Dourados, v. 7, n. 26, p.560-569, 2014.

EIRAS, P. P.; COELHO, F. C. Utilização de leguminosas na adubação verde para a cultura do milho. Revista Científica Internacional, Campos dos Goytacazes, v. 1, n. 17, p.96-124, 2011.

FARIAS, L.N.; BONFIM-SILVA, E.M.; PIETRO-SOUZA, W.; VILARINHO, M.K.C.; SILVA, T.J.A.; GUIMARÃES, S.L. Características morfológicas e produtivas de feijão guandu anão cultivado em solo compactado. Revista Brasileira de Engenharia Agrícola e Ambiental, Campina Grande, v. 17, n. 5, p.497-503, 2013.

FERREIRA, D. F. Sisvar: a Guide for its Bootstrap procedures in multiple comparisons. Ciência e Agrotecnologia, Lavras, v. 38, n. 2, p.109-112, 2014.

FOLONI, J. S. S.; LIMA, S. L.; BÜLL, L. T. Crescimento aéreo e radicular da soja e de plantas de cobertura em camadas compactadas de solo. Revista Brasileira de Ciência do Solo, Viçosa, v. 30, n.1, p.49-57, 2006.

GUBIANI, P. I.; REICHERT, L. M.; REINERT, D. J. Indicadores hídricos-mecânicos de compactação do solo e crescimento de plantas. Revista Brasileira de Ciência do Solo, Viçosa, v. 37, n. 1, p.1-10, 2013.

HUCK, M. G.; KLEPPER, B.; TAYLOR, H. M. Diurnal variations in root diameter. Plant Physiology, Bethesda, v. 45, p.529-530, 1970.

JORGE, L. A. C.; SILVA, D. J. C. Safira: Sistema de análise de fibras e raízes. São Carlos: Embrapa Instrumentação Agropecuária, 2010. 21p.

LEAL, A. J. F.; LAZARINI, E.; RODRIGUES, L. R.; MARCANDALLI, L. H. Adubação nitrogenada para milho com o uso de plantas de cobertura e modos de aplicação de calcário. Revista Brasileira de Ciência do Solo, Viçosa, v. 37, n. 1, p.491-501, 2013.

LIMA, L. B.; PETTER, F. A.; LEANDRO, W. M. Desenvolvimento de plantas de cobertura sob níveis de compactação em Latossolo de Cerrado. Revista Brasileira de Engenharia e Agricultura Ambiental, Campina Grande, v. 19, n. 11, p.1064-1071, 2015.

MACHADO, A. L. T.; REIS, A. V.; FERREIRA, M. F. P.; MACHADO, R. L. T.; MACHADO, A. L. C.; BAUER, G. B. Influência da pressão de inflação do pneu do trator na 
resistência do solo à penetração. Revista Brasileira de Agrociência, Pelotas, v. 11, n. 1, p.481-486, 2005.

MALAVOLTA E. Manual de nutrição mineral de plantas. São Paulo: Agronômica Ceres, 2006. $631 \mathrm{p}$.

MONTANARI, R.; ZAMBIANCO, E. C.; CORREA, A. R.; PELLIN, D. M. P.; PASSOS, M.; DALCHIAVON, F. C. Atributos físicos de um Latossolo Vermelho correlacionados linear e espacialmente com a consorciação de guandu com milheto. Revista Ceres, Viçosa, v. 59, n. 1, p.125-135, 2012.

OlIVEIRA, P. R.; CENTURION, J. F.; CENTURION, A. P. C.; FRANCO, H. B. J.; PEREIRA, F. S.; BÁRBARO JÚNIOR, L. S.; ROSSETTI, K. V. Qualidade física de um Latossolo vermelho cultivado com soja submetido a níveis de compactação e de irrigação.

Revista Brasileira de Ciência do Solo, Viçosa, v. 36, n. 1, p.587-597, 2012.

PADOVAN, M. P.; MOTTA, I. S.; CARNEIRO, L. F.; MOITINHO, M. R.; FERNANDES, S. S. L. Acúmulo de fitomassa e nutrientes e estádio mais adequado de manejo do feijão-deporco para fins de adubação verde. Revista Brasileira de Agroecologia, Rio de Janeiro, v. 6, n. 3, p.182-190, 2011.

PAGLIAI, M.; MARSILI, A.; SERVADIO, P.; VIGNOZZI, N.; PELlEGRINI, S. Changes in some physical properties of a clay soil in central italy following the passage of rubber tracked and wheeled tractors of médium power. Soil Tillage Research, [s. l.], v. 73, n. 1, p.119-129, 2003.

REINERT, D. J.; ALBUQUERQUE, J. A.; REICHERT, J. M.; AITA, C.; ANDRADE, M. M. C. Limites críticos de densidade do solo para o crescimento de raízes de plantas de cobertura em Argissolo Vermelho. Revista Brasileira de Ciência do Solo, Viçosa, v. 32, n. 1, p.18051816, 2008.

SANTOS, H. G.; JACOMINE, P. K. T.; ANJOS, L. H. C.; OLIVEIRA, V. A.; LUMBRERAS, J. F.; COELHO, M. R.; ALMEIDA, J. A.; ARAÚJO FILHO, J. C.; OLIVEIRA, J. B; CUNHA, T. J. F. Sistema brasileiro de classificação de solos. Brasília: EMBRAPA, 2018. 356 p.

SCAPINELli, A.; DEINA, F. R.; VALADÃO JÚNIOR, A. D.; VALADÃO, F. C. A.; PEREIRA, L. B.; Sistema radicular e componentes produtivos do girassol em solo compactado. Bragantia, Campinas, v. 75, n. 4, p.474-486, 2016.

SODRÉ FILHO, J.; CARDOSO, A. N.; CARMONA, R.; CARVALHO, A. M. Fitomassa e cobertura do solo de culturas de sucessão ao milho na Região do Cerrado. Pesquisa Agropecuária Brasileira, Brasília, v. 39, n. 4. p.327-334, 2004.

TEIXEIRA, P. C.; DONAGEMMA, G. K.; FONTANA, A.; TEIXEIRA, W. G. Manual de métodos de análise de solo. Brasília: Embrapa, 2017. 575 p.

TEODORO, R. B.; OLIVEIRA, F. L.; SILVA, D. M. N.; FÁVERO, C.; QUARESMA, M. A. L. Aspectos agronômicos de leguminosas para adubação verde no cerrado do alto vale do Jequitinhonha. Revista Brasileira de Ciência do Solo, Viçosa, v. 35, n. 1, p.635-643, 2011. 
VALADÃO, F. C. A.; WEBER, O. L. S.; VALADÃO JÚNIOR, D. D.; SCAPINELLI, A.; DEINA, F. R.; BIANCHINI, A. Adubação fosfatada e compactação do solo: Sistema radicular da soja e do milho e atributos físicos do solo. Revista Brasileira de Ciência do Solo, Viçosa, v. 39, n. 1, p.243-255, 2015. 